$12.1 ; 12.3$

\title{
Катодный узел сильноточной электронной пушки с многоканальным инициированием эмиссии пробоем по поверхности диэлектрика
}

\author{
(С) П.П. Кизириди, Г.Е. Озур \\ Институт сильноточной электроники СО РАН, Томск, Россия \\ E-mail: kiziridi_pavel@mail.ru
}

Поступило в Редакцию 30 апреля 2020г.

В окончательной редакции 6 мая 2020г.

Принято к публикации 6 мая 2020г.

\begin{abstract}
Представлена новая схема катодного узла сильноточной электронной пушки. Инициирование взрывной эмиссии осуществляется с помощью 69 параллельно срабатывающих искровых промежутков, электроды и трубчатые керамические изоляторы которых встроены в дисковый взрывоэмиссионный катод. Продемонстрированы работоспособность предложенной схемы и высокая эмиссионная способность катодного узла, примерно в 1.5-1.7 раза превосходящая эмиссионную способность, характерную для традиционной схемы пушки с плазменным анодом и медно-оплеточным взрывоэмиссионным катодом.
\end{abstract}

Ключевые слова: сильноточные электронные пучки, взрывная эмиссия, катодный узел, многоканальное инициирование, пробой по поверхности диэлектрика.

DOI: 10.21883/PJTF.2020.15.49750.18364

Низкоэнергетические $(10-30 \mathrm{keV})$ сильноточные (до $25 \mathrm{kA}$ ) электронные пучки (НСЭП) широко используются для модификации поверхностных слоев металлических материалов уже несколько десятков лет [1-3]. Формирование таких пучков осуществляется, как правило, в пушках с плазменным анодом и взрывоэмиссионным катодом. Высокая плотность энергии (до $20 \mathrm{~J} / \mathrm{cm}^{2}$ ) и короткая длительность импульса $(2-4 \mu \mathrm{s})$ позволяют выделить энергию пучка в тонком (доли-единицы микрометров) поверхностном слое, доводя его до плавления и даже частичного испарения. Разработанные нами источники НСЭП нашли применение не только в физическом эксперименте, но и на практике $[4,5]$.

Однако существуют проблемы стабильности работы сильноточных электронных пушек и однородности распределения плотности энергии по сечению пучка, которые особенно критичны при решении задач, связанных с формированием поверхностных сплавов. Свойства поверхностных сплавов весьма чувствительны к распределению легирующих элементов по глубине [6], что определяется разбросом плотности энергии НСЭП в серии импульсов. В немалой степени решение этих проблем связано с обеспечением устойчивости функционирования одного из ключевых элементов электронной пушки - взрывоэмиссионного катода. Поскольку возбуждение взрывной эмиссии резко зависит от напряженности поля на катоде [7], а в нашем случае значение ускоряющего напряжения относительно невелико (до $30 \mathrm{kV}$ ), решение этой задачи становится весьма непростым, особенно для катодов большой площади. Даже бомбардировка поверхности катода ионами плазменного анода, стимулирующая образование взрывоэмиссионных центров $[4,7]$, не позволяет в полной мере решить проблему стабильности работы катода.
Предварительное создание плазмы в катодном узле является давно известным и широко применяемым методом при разработке источников интенсивных электронных пучков. Прежде всего необходимо отметить классические системы с плазменным катодом и сеточной стабилизацией эмиссии $[8,9]$, в которых плазма создается вспомогательным импульсным дуговым или тлеющим разрядом, заполняет полый электрод с сеткой, через которую эмитируемые электроны выходят в ускоряющий зазор. Ускоряющее напряжение в таких системах обычно статическое и поддерживается во время импульса большой емкостью. Такие системы обеспечивают сравнительно низкую плотность эмиссионного тока (не более $10 \mathrm{~A} / \mathrm{cm}^{2}$ ), но большую длительность импульса (до сотен микросекунд). Также низкую плотность тока (не более $30 \mathrm{~A} / \mathrm{cm}^{2}$ ) дают системы с незавершенным емкостным разрядом по поверхности диэлектрика, и только системы с завершенным разрядом дают плотность тока на один-два порядка величины больше, т. е. обеспечивающую генерацию именно сильноточных пучков [10].

В работе [11] описан ускоритель электронов, предназначавшийся для накачки газовых лазеров $(200 \mathrm{keV}$, $200 \mathrm{~A}, 10.2 \mu \mathrm{s})$. Катодный узел содержал 48 резистивно развязанных дисковых эмиттеров, инициируемых пробоем по поверхности диэлектрика при подаче на них высоковольтного импульса через повышающий трансформатор. Плазма, возникающая при пробое этих 48 промежутков между дисками-эмиттерами и катодом, является эмиттером электронов. Эмитированные электроны ускорялись в сторону сетки, заземленной через резистор. Электроны, осевшие на сетке, создавали отрицательное смещение, а электроны, прошедшие сквозь нее, ускорялись к аноду, и тем самым формировался электронный пучок. 


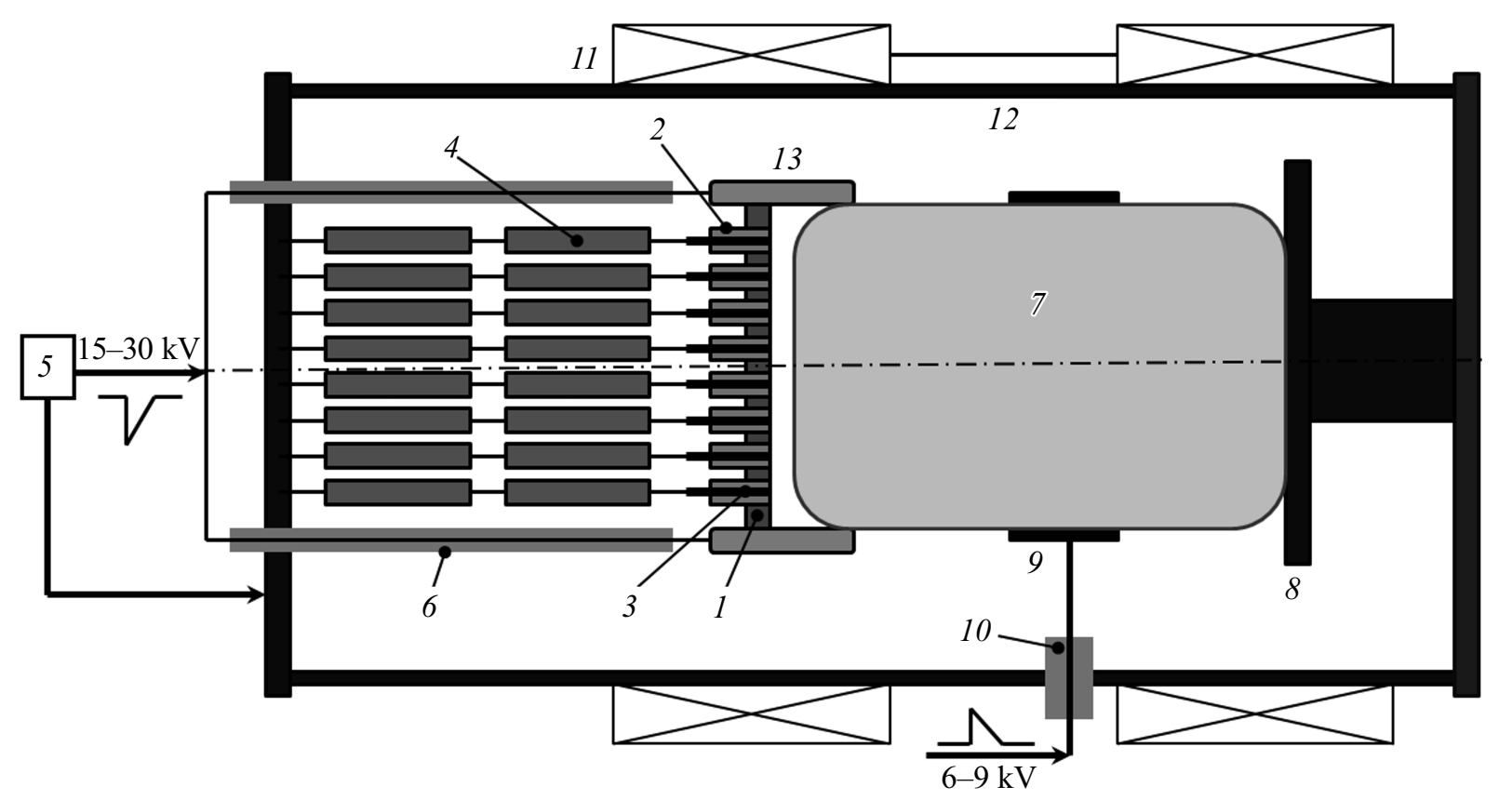

Рис. 1. Принципиальная схема электронной пушки и ее катодного узла. Пояснения в тексте.

Из сильноточных источников электронов следует отметить установку, описанную в [12]. Катодный и анодный узлы включали блоки из нескольких искровых источников плазмы. После заполнения ускоряющего зазора и пространства дрейфа пучка плазмой (это занимало несколько микросекунд) на катод подавался импульс ускоряющего напряжения амплитудой до 60-80 kV. Амплитуда тока пучка, регистрируемого цилиндром Фарадея, достигала $50 \mathrm{kA}$. Авторы [12], однако, ошибочно полагали, что данный ток обеспечивается предварительно созданной плазмой искровых источников. Для обеспечения отбираемой с катода плотности тока $\left(\sim 10-20 \mathrm{kA} / \mathrm{cm}^{2}\right)$ концентрация катодной плазмы должна быть на уровне $(3-5) \cdot 10^{14} \mathrm{~cm}^{-3}$, а не $10^{12}-10^{13} \mathrm{~cm}^{-3}$, как это было измерено авторами [12]. Плотная же плазма генерируется катодными пятнами, возникающими при подаче ускоряющего напряжения на катод.

Характерной чертой всех описанных выше установок является раздельное электропитание источников плазмы и ускоряющего зазора между катодом и анодом (коллектором). Вследствие этого возникает необходимость высоковольтной развязки между блоками питания, а при импульсном питании ускоряющего зазора (как, например, в [11]) - синхронизации блоков питания.

Мы предлагаем новую и весьма простую схему катодного узла, приведенную на рис. 1. Катодный узел включает в себя взрывоэмиссионный катод 1 в виде перфорированного медного диска диаметром $58 \mathrm{~mm}$, в отверстия которого заподлицо вставлены керамические трубки 2 и медные электроды 3. Наружный диаметр трубок составляет $4 \mathrm{~mm}$, внутренний $-2 \mathrm{~mm}$; диаметр электродов также равен $2 \mathrm{~mm}$. Каждый из 69 электродов (межцентровое расстояние составляет $5.5 \mathrm{~mm}$ ) заземлен через резисторы 4 сопротивлением $2 \mathrm{k} \Omega$ (два резистора номиналом $1 \mathrm{k} \Omega$ ). Для некоторого усиления электрического поля и локальной фокусировки ионного потока из плазменного анода на рабочей поверхности катода нарезаны кольцевые канавки треугольного сечения.

При подаче на катод высоковольтного импульса отрицательной полярности амплитудой $15-30 \mathrm{kV}$ от генератора 5 (через проходные изоляторы 6) происходит пробой по поверхности торцов керамических трубок, и возникает плазма, состоящая из материалов катода (катодные пятна), керамических трубок и электродов, a также ионизованного десорбированного газа. Образование катодных пятен при протекании тока через поджигающие промежутки (эти пятна можно назвать затравочными) обеспечивается тем, что амплитуда тока (7-12 A) через каждый промежуток превышает так называемый пороговый ток дуги [13], который составляет доли-единицы ампер практически для всех материалов (например, для меди он равен около $3 \mathrm{~A}$ ). Электроны, эмитируемые затравочными, а также возникшими в течение импульса катодными пятнами, ускоряются в двойном слое между плазмой катодных пятен и предварительно созданным плазменным анодом 7 и транспортируются к заземленному коллектору 8. Рост тока обеспечивается как увеличением числа катодных пятен, так и их расширением, т.е. увеличением площади эмиссионной поверхности [4,7]. Плазменный анод, имеющий потенциал, практически равный потенциалу коллектора, создается с помощью сильноточного отражательного разряда при подаче импульса положитель- 

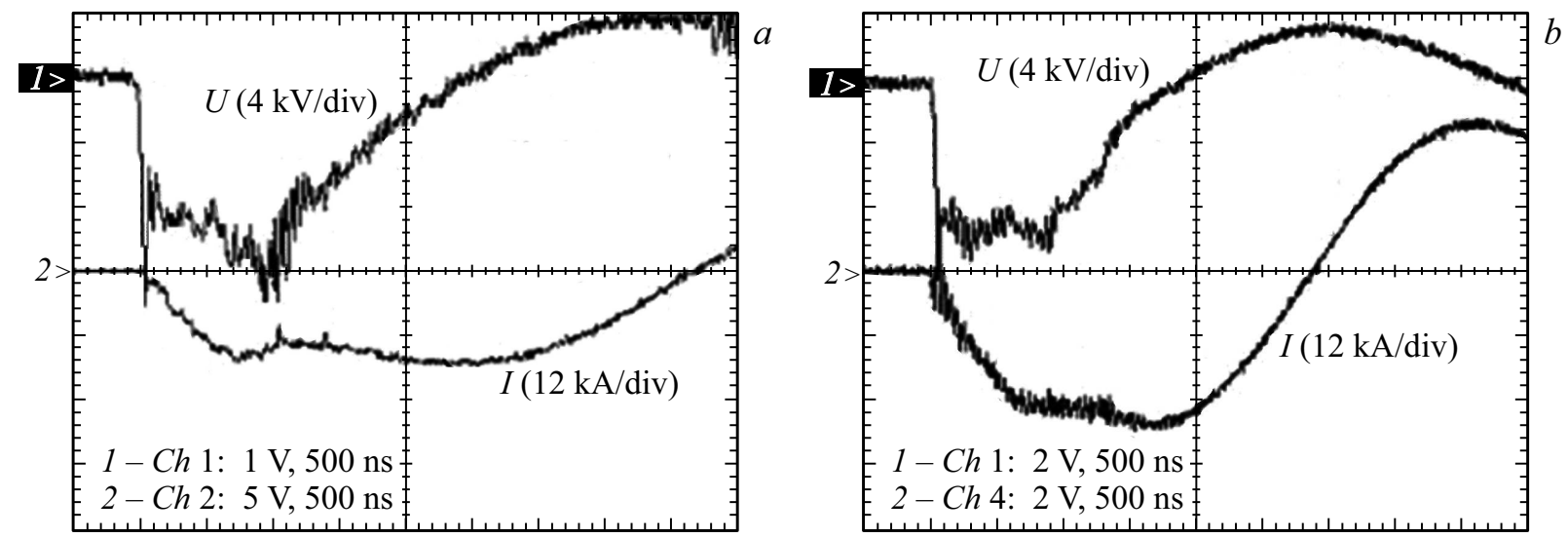

Рис. 2. Типичные осциллограммы импульсов ускоряющего напряжения и тока катода. $a-$ в случае медно-оплеточного катода [4], $b-$ в случае нового катодного узла с многоканальным инициированием.

ной полярности на кольцевой металлический анод 9 через проходной изолятор 10. Зажигание и горение сильноточного отражательного разряда обеспечивается продольным магнитным полем, создаваемым соленоидом 11, которое также обеспечивает транспортировку пучка к коллектору [4]. Отметим, что данное магнитное поле не препятствует пробою поджигающих промежутков, поскольку при типичных значениях его индукции $0.1-0.2 \mathrm{~T}$ ларморовский радиус электронов с энергией $>15 \mathrm{keV}$ в несколько раз превышает расстояние по поверхности торца диэлектрической трубки, поперек которого развивается пробой. Для уменьшения вероятности попадания электронов катодной плазмы на стенку корпуса пушки 12 установлен экранный электрод 13, электрически соединенный с катодом.

Предложенный катодный узел был успешно испытан. На рис. 2 приведены характерные осциллограммы ускоряющего напряжения $(U)$ и тока катода $(I)$, полученные в случае медно-оплеточного катода [4] с диаметром эмитирующей части $62 \mathrm{~mm}$ (рис. $2, a$ ) и в случае нового катодного узла с многоканальным инициированием (рис. $2, b$ ). Видно, что новый катодный узел обеспечивает не только больший ток, но и увеличенную скорость его нарастания, несмотря на несколько меньшую (на 14\%) площадь эмитирующей части катода.

Отметим, что предлагаемая схема катодного узла лучше всего применима при сравнительно небольших (десятки $\mathrm{kV}$ ) ускоряющих напряжениях ввиду проблемы обеспечения стойкости резисторов при более высоких напряжениях. Вероятно, по этой причине такая схема, несмотря на свою простоту, ранее не применялась, поскольку большинство источников электронов разрабатывалось для сравнительно высоких ускоряющих напряжений $(>100 \mathrm{kV})$. Кроме того, нерационально использовать чрезмерно высокие напряжения для инициирования вспомогательных разрядов.

Таким образом, впервые создан и испытан катодный узел, включающий собственно взрывоэмиссионный катод и встроенные в него искровые источники плазмы, инициируемые пробоем по поверхности диэлектрика. Отличительной чертой нового катодного узла является его питание от одного генератора высоковольтных импульсов, обеспечивающего как срабатывание источников плазмы, так и ускорение электронов пучка к коллектору. Установлено, что такой катод обладает повышенной (на данный момент примерно в $1.5-1.7$ раза) эмиссионной способностью по сравнению с традиционной схемой формирования пучка в пушках с плазменным анодом и медно-оплеточным взрывоэмиссионным катодом. Предлагаемая схема может успешно использоваться и без предварительного заполнения пространства между катодом и коллектором плазмой от постороннего источника, т.е. для случая вакуумного диода, но, конечно, при существенно меньших расстояниях между катодом и коллектором (единицы сантиметров).

\section{Конфликт интересов}

Авторы заявляют, что у них нет конфликта интересов.

\section{Список литературы}

[1] Proskurovsky D.I., Rotshtein V.P., Ozur G.E., Markov A.B., Nazarov D.S., Shulov V.A., Ivanov Yu.F., Buchheit R.G. // J. Vac. Sci. Technol. A. 1998. V. 16. P. 2480-2488.

[2] Uno Y., Okada A., Uemura K., Raharjo P., Furukawa T., Karato K. // Precis. Eng. 2005. V. 29. P. 449-455.

[3] Murray J.W., Clare A.T. // J. Mater. Process. Technol. 2012. V. 212. P. 2642-2651.

[4] Озур Г.Е., Проскуровский Д.И. // Физика плазмы. 2018. T. 44. № 1. C. 21-44. DOI: $10.7868 / \mathrm{S} 0367292118010146$

[5] Uno Y., Okada A., Uemura K., Raharjo P., Sano S., Yu Z., Mishima S. // J. Mater. Process. Technol. 2007. V. 187-188. P. 77-80.

[6] Meisner L.L., Markov A.B., Rotshtein V.P., Ozur G.E., Meisner S.N., Yakovlev E.V., Semin V.O., Mironov Yu.P., Poletika T.M., Girsova S.L., Shepel D.A. // J. Alloys Compd. 2018. V. 730. P. 376-385. DOI: 10.1016/j.jallcom.2017.09.238 
[7] Месяи Г.А., Проскуровский Д.И. Импульсный электрический разряд в вакууме. Новосибирск: Наука, 1984. 256 с.

[8] Крейндель Ю.Е. Плазменные источники электронов. М.: Атомиздат, 1977. $144 \mathrm{c}$.

[9] Окс E.M. Источники электронов с плазменным катодом: физика, техника, применения. Томск: Изд-во НТЛ, 2005. $216 \mathrm{c}$.

[10] Бугаев С.П., Шпак В.Г. Об использовании скользящего разряда в вакууме в качестве управляемого эмиттера электронов // Мощные наносекундные импульсные источники ускоренных электронов / Под ред. Г.А. Месяца. Новосибирск: Наука, 1974. С. 71-76.

[11] Loda G., Schneider S., Otto W.F., Dezenberg G.J. // Proc. 4th IEEE Pulsed Power Conf. Albuquerque, New Mexico, USA, 1983. P. 486-489.

[12] Иремашвили Д.В., Курильников С.В., Леонтьев Н.И., Осепашвили Т.А. // Письма в ЖЭТФ. 1973. Т. 17. В. 1. C. 11-13.

[13] Кесаев И.Г. Катодные процессы электрической дуги. М.: Наука, 1968. 244 c. 